\title{
NBR 15575, ADEQUAÇÃO AMBIENTAL E AVALIAÇÃO DE DESEMPENHO
}

\section{NBR 15575, ENVIRONMENTAL SUITABILITY AND PERFORMANCE EVALUATION}

\author{
ALDO RIBEIRO DE CARVALHO | UFJF \\ VITOR DIAS LOPES NUNES | UFJF \\ DIANA FIORI RUBIM | UFJF \\ MARIA APARECIDA STEINHERZ HIPPERT, Dra. | UFJF
}

\begin{abstract}
RESUMO
A NBR 15575 entrou em vigor em 2013 e pode ser considerada uma oportunidade de melhoria da qualidade das habitações brasileiras, representando um avanço em seus aspectos ambientais, sociais e econômicos. Tendo em vista a relevância da norma para a construção civil e o impacto ambiental dessa indústria, o presente trabalho tem por objetivo identificar e analisar, com base nos estudos que vem sendo realizados sobre a norma de desempenho brasileira, aqueles que relacionam a norma de desempenho à adequação ambiental, bem como a comparação com normas de desempenho de outros países e selos de certificação ambiental, de maneira a identificar a contribuição dos aspectos ambientais da NBR 15575 a serem considerados nas edificações habitacionais, além de fomentar discussões sobre adequação ambiental e a norma de desempenho. Para isso, utilizou-se como metodologia de pesquisa a Revisão Sistemática da Literatura (RSL) abrangendo o período de 2008 a 2018. Como principais resultados identifica-se, no âmbito da NBR 15575, estudos que tratam do uso de materiais inovadores para redução do impacto ao meio ambiente e aumento o desempenho da edificação, além da identificação das barreiras que dificultam o empreendimento de serem sustentáveis. Além disso, ao comparar a norma brasileira com outros documentos, verificou-se a distinção entre a forma de divulgação e aplicação dos sistemas avaliativos, os critérios e exigências entre os documentos, as dificuldades de aplicação e a existência de fiscalização para o cumprimento dos códigos. Tem-se como contribuição uma maior divulgação da NBR 15575, seus aspectos ambientais, e aumento da discussão e conhecimento sobre o tema.
\end{abstract}

PALAVRAS CHAVE: NBR 15575; Desempenho; Certificação Ambiental; Adequação Ambiental

\begin{abstract}
NBR 15575 came into force in 2013 and can be considered as an opportunity to improve the quality of Brazilian housing, representing an advance in its environmental, social, economic aspects. Given the relevance of the standard for civil construction and the environmental impact of this industry, this paper aims to identify and analyze, based on studies that are being conducted on the Brazilian performance standard, those that relate the performance standard environmental adequacy, as well as the comparison with performance standards of other countries and environmental certification seals, in order to identify the contribution of the environmental aspects of NBR 15575 to be considered in housing buildings, in addition to fostering discussions about environmental adequacy and the standard of performance. For this, it was used as research methodology the Systematic Literature Review (SLR) covering the time period from 2008 to 2018. The use of keywords and search criteria made it possible to compile the works on NBR 15575 and among them to highlight those related to Environmental Adequacy to the comparative with environmental stamps and codes from other countries. As main results, it is identified, within the scope of NBR 15575, studies that deal with the use of innovative materials to reduce the impact to the environment and increase the performance of the building, in addition to the identification of barriers that hinder the enterprise to be sustainable. In addition, when comparing
\end{abstract}


the Brazilian standard with other documents, a distinction was noticed between the form of disclosure and application of the evaluation systems, the criteria and requirements of the documents, the difficulties of application, and the existence of inspection for compliance codes. The contribution is made of a greater dissemination of NBR 15575, its environmental aspects, and an increase in the discussion and knowledge on the subject.

KEY WORDS: NBR 15575; Performance; Environmental Certification; Environmental suitability 


\section{INTRODUÇÃO}

A construção civil possui relação direta com o desenvolvimento econômico e social das cidades, no entanto, gera impactos ambientais em larga escala. Ela é responsável por aproximadamente $35 \%$ dos resíduos sólidos gerados no mundo e o descarte irregular desses materiais é uma prática comum e crescente que gera impactos no meio ambiente e na sociedade, como o uso e ocupação irregular do solo e a poluição de mananciais (DUAN; LI, 2016; WANG et al, 2018; MAUÉS et al, 2020). A construção civil é responsável ainda por um grande consumo de água, seja na fabricação de insumos utilizados ou no canteiro de obra, além de despender quantidade de energia apreciável (ZHU et al, 2019; SOUZA; GHISI, 2020).

A fim de reduzir a degradação ambiental promovida por esse setor produtivo, é necessária a implantação de conceitos de gestão ambiental, através de objetivos bem definidos, os quais devem ser alcançados pelo empreendimento. Como resultado, serão obtidas obras mais racionais, eficientes e edificações com maiores níveis de desempenho (REZENDE; BRITO; FREITAS, 2017).

Nesse contexto, muitas ferramentas de avaliação de desempenho e qualidade ambiental foram desenvolvidas em vários países - Estados Unidos, Canadá, França, Portugal, entre outros - que envolvem a avaliação de cenários alternativos com base em diferentes critérios como, por exemplo, ambientais (consumo de energia, emissões de CO2, desempenho ambiental), econômicos (custos do ciclo de vida, custo de capital, durabilidade) e sociais (custo térmico e acústico, qualidade do ar)(DOAN et al, 2017; LÓPEZ et al, 2019). Isto resulta em edificações com maior eficiência energética, maior qualidade dos ambientes internos e bem-estar do usuário durante todo ciclo de vida da edificação (PELLIZZETTI, 2017; LEE, 2019).

As ferramentas de certificação ambiental avaliam o empreendimento a partir de Indicadores de desempenho (qualitativos e quantitativos), atribuindo pontuações técnicas em função do comprometimento aos requisitos estabelecidos para a concretização de uma "construção sustentável" (MATEUS; BRAGANÇA, 2011). Dessa forma, estimulam práticas sustentáveis, lideranças ambientais e promovem a valorização do empreendimento e conscientização do consumidor (LACERDA; CARSALADE; ASSIS, 2018).

O desenvolvimento sustentável, segundo o Relatório de Bundtland (1987), é aquele que "atende às necessidades do presente sem comprometer a possibilidade de as gerações futuras atenderem suas próprias necessidades". Para o Brasil, ele é mensurado de acordo com aspectos ambientais, sociais, econômicos e institucionais (IBGE, 2020). Nesse sentido é importante o papel da legislação e das diretrizes brasileiras, que atuam direta ou indiretamente, tornar os empreendimentos mais sustentáveis. Dentre elas pode-se citar a NBR 15575 - Norma de Desempenho.

A NBR 15575 estabelece o conceito de desempenho por meio da definição de requisitos (qualitativos), critérios (quantitativos ou premissas) e métodos de avaliação, objetivando a mensuração clara do seu cumprimento (ABNT, 2013). Cabe ressaltar que apesar de não serem lei, as normas técnicas têm obrigatoriedade de atendimento assegurada pelo Código de Defesa do Consumidor (Lei 8078, de 11.09.1990), enquanto as ferramentas de certificação ambiental como o AQUA e o LEED, têm caráter facultativo.

Neste contexto, o presente trabalho tem por objetivo levantar e analisar dentre os estudos já realizados sobre a Norma de Desempenho, obtidos através de uma revisão sistemática de literatura (RSL), aqueles que relacionam a NBR 15575 à adequação ambiental, bem como a comparação com normas de desempenho de outros países e selos de certificação ambiental, de maneira a identificar a contribuição dos aspectos ambientais da NBR 15575 a serem considerados nas edificações habitacionais, além de fomentar discussões sobre adequação ambiental e a norma de desempenho brasileira.

\section{REFERÊNCIAL TEÓRICO}

\subsection{NBR 15575 e a exigência de Adequação Ambiental}

O conceito de desempenho vem sendo estudado desde a década de 60 , contudo até o final da década de 80 estava voltado para o desenvolvimento teórico (BORGES; SABBATINI, 2008). Na década de 90 , iniciou-se a aplicação do conceito para a concepção e execução de construções. A partir de 1992 países Europeus, como Dinamarca, Holanda, Espanha e Reino Unido, iniciaram ações e programas para avaliar o desempenho do consumo de energia das edificações (BORGES; SABBATINI, 2008; KERN; SILVA; KAZMIERCZAK, 2014).

Nos Estados Unidos, por exemplo, as questões sobre desempenho de edificações só começaram a ser regulamentadas após a criação da primeira versão do International Residential Code (IRC) nos anos 2000, tendo uma segunda versão em 2009, e a mais recente do ano de 2012 (MIRANDA, 2017). Na Espanha, a questão de desempenho foi oficializada em 2006 com a publicação do Código Técnico das Edificações (CTE) (KERN; SILVA; KAZMIERCZAK, 2014). 
No Brasil, o conceito de desempenho começou a evoluir a partir da década de 80, principalmente devido aos trabalhos do Instituto de Pesquisas Tecnológicas (IPT) para o Banco Nacional da Habitação, e depois para a Caixa Econômica Federal. Nos anos 2000, a Caixa financiou um projeto para a criação de um programa de avaliação de sistemas construtivos inovadores baseado no conceito de desempenho. (KERN; SILVA; KAZMIERCZAK, 2014). Este projeto resultou na publicação do conjunto de normas ABNT NBR 15575, que publicadas inicialmente em 2008, foram revisadas e passaram a vigorar em 2013. A preocupação com desempenho da edificação ainda se faz presente em âmbitos internacionais em 2019, e ratifica que a mensuração do desempenho de um empreendimento deve ser dada através de parâmetros que reflitam as necessidades dos usuários, tal qual acontece com a NBR 15575, no Brasil (WILDE, 2019).

A NBR 15575 está dividida em seis partes segundo os sistemas que compõe a edificação, sendo elas: Requisitos gerais; Requisitos para os sistemas estruturais; Requisitos para o sistema de piso; Requisito para os sistemas de vedações verticais internas e externas; Requisito para os sistemas de cobertura, Requisitos para os sistemas hidrossanitários.

Cada uma das seis partes da norma é repartida em critérios, tendo por base as exigências dos usuários divididas em segurança, habitabilidade e sustentabilidade (Quadro 1).

A sustentabilidade compreende o atendimento aos critérios de durabilidade, manutenibilidade e adequação ambiental. Quanto à adequação ambiental, a ABNT NBR 15575/2013 aponta que a sua avaliação junto às atividades da indústria da construção ainda são objetos de pesquisa e, com o atual estado-da-arte, não é possível estabelecer critérios e métodos de avaliação para expressar os impactos ambientais. Deste modo, a norma apresenta algumas recomendações gerais para os empreendimentos e infraestrutura, os quais devem ser construídos de maneira a minimizar o impacto no ambiente.

\begin{tabular}{|l|}
\hline Segurança \\
\hline - Segurança estrutural; \\
- Segurança contra fogo; \\
- Segurança no uso e na operação. \\
\hline Habitabilidade \\
\hline - Estanqueidade; \\
- Desempenho térmico; \\
- Desempenho acústico; \\
- Desempenho lumínico; \\
- Saúde, higiene e qualidade do ar; \\
- Funcionalidade e acessibilidade; \\
- Conforto tátil e antropodinâmico. \\
\hline
\end{tabular}

\begin{tabular}{|l|}
\hline Sustentabilidade \\
\hline - Durabilidade; \\
- Manutenibilidade; \\
- Adequação ambiental. \\
\hline
\end{tabular}

Quadro 1 - Exigências dos usuários Fonte: Adaptado de ABNT (2013)

Um resumo das recomendações proposto pela Norma de Desempenho para atendimento à exigência de adequação ambiental é apresentado no Quadro 02.

\begin{tabular}{|l|l|}
\hline Aspectos considerados & Recomendações \\
\hline $\begin{array}{l}\text { Projeto e implantação } \\
\text { de empreendimentos }\end{array}$ & $\begin{array}{l}\text { Deve ser considerado quaisquer riscos } \\
\text { durante a implantação do empreen- } \\
\text { dimento, tais como: deslizamentos } \\
\text { de taludes, enchentes, erosões, } \\
\text { assoreamento, dentre outros. }\end{array}$ \\
\hline $\begin{array}{l}\text { Seleção e consu- } \\
\text { mo de materiais }\end{array}$ & $\begin{array}{l}\text { Os empreendimentos devem ser } \\
\text { construídos a partir da exploração } \\
\text { e consumo racional dos recursos } \\
\text { naturais, visando de toda forma } \\
\text { menor impacto ambiental. }\end{array}$ \\
\hline $\begin{array}{l}\text { Consumo de água e depo- } \\
\text { sição de esgotos no uso e } \\
\text { ocupação da habitação }\end{array}$ & $\begin{array}{l}\text { Os sistemas hidrossanitários devem } \\
\text { estar de acordo com a ABNT NBR } \\
\text { 15097-1 e as águas provenientes dos } \\
\text { mesmos devem ser encaminhadas } \\
\text { às redes públicas de coleta, e na } \\
\text { ausência dessas fazer uso de soluções } \\
\text { que evitem contaminação local. }\end{array}$ \\
\hline $\begin{array}{l}\text { Consumo de energia } \\
\text { no uso e ocupação } \\
\text { da habitação }\end{array}$ & $\begin{array}{l}\text { Reduzir o consumo de energia } \\
\text { através de sistemas eficientes e } \\
\text { utilização de energias alternativas. }\end{array}$ \\
\hline
\end{tabular}

Quadro 2 - Recomendações quanto à adequação ambiental

Fonte: Adaptado de ABNT (2013)

\subsection{Certificação ambiental}

A certificação ambiental tem o objetivo de estimular as práticas sustentáveis na indústria da construção civil e para isso direciona projetistas, construtores, fornecedores e toda a cadeia produtiva em prol da construção verde (CANAZARO; KERN, 2018). Essas ferramentas de avaliação ambiental devem ser desenvolvidas ou adequadas a realidade local de cada país, visando potencializar o desempenho ambiental do empreendimento avaliado (SILVA, 2003; ZARGHAMI; FATOUREHCI, 2020).

Os sistemas de avaliação possuem estruturas simplificadas, geralmente em forma de lista de requisitos (check list). A metodologia é prescritiva, havendo um conjunto de requisitos e critérios estipulados, mas sem a preocupação de se atender a níveis mínimos de desempenho. Assim, conforme os quesitos são contemplados, a edificação acumula pontos que somados possibilitarão o empreendimento obter a certificação ambiental (SILVA, 2007; MATOS, 2014). 
As ferramentas de avaliação ambiental em empreendimentos sustentáveis mais utilizados pelos países são: BREEAM, LEED, SBTool, Green Star, CASBEE, AQUA e ISSO 21931-1. AQUA, LEED e ISO 21931-1 (CARGHAMI; FATOUREHCI, 2020; COSTA et al., 2015). No Brasil, por sua vez, o AQUA, o LEED, PROCEL e Selo Casa Azul são as ferramentas que mais se destacam.

O selo AQUA, adaptado do francês HQE para o contexto brasileiro, realiza a verificação da alta qualidade ambiental do empreendimento através de auditorias independentes. Dada as dimensões continentais do Brasil e as diversas zonas bioclimáticas, o sistema possui expressiva representatividade e traz grande interesse para o estudo das especificidades regionais dado seus critérios avaliativos (TIBÚRCIO; OLIVEIRA, 2018). A Fundação Vanzolini fornece o selo para os empreendimentos nacionais, que devem possuir controle total do projeto em todas as suas fases: Programa, Concepção (Projeto), Realização (Obra) e Operação (Uso). Assim, é necessária a realização de um sistema de gestão do empreendimento, para que sejam atendidos os critérios de desempenho da Qualidade Ambiental do Edifício (COSTA et al., 2015). Apesar do AQUA ser amplamente utilizado, no Brasil o líder em quantidade de uso é o selo americano LEED - Leadership In Energy and Environmental Design (PROVENZANO; BASTOS, 2017).

O selo LEED foi criado em 1998 pela organização não governamental United States Green Building Council. A edificação recebe a certificação ambiental LEED se cumprir os pré-requisitos e créditos comprovando o uso de práticas de sustentabilidade atreladas ao projeto, as quais percorrem oito categorias: Inovação e Projeto,

Localização e Transporte, Implantação Sustentável, Uso Racional da Água, Energia e Atmosfera, Materiais e Recursos, Qualidade Ambiental Interna e Práticas Sociais (JALAEl; JALAEI; MOHAHAMMADI, 2019). De maneira geral, a obtenção de certificação ambiental garante ao proprietário que seu investimento foi executado de acordo com o planejado, acarretando na redução de custos, melhoria da eficiência hídrica e energética e aumento da qualidade dos ambientes (PELLIZZETTI, 2017).

No Brasil não há uma certificação oficial para aferição dos critérios de sustentabilidade das edificações. O selo PROCEL Edifica, desenvolvido pela Eletrobrás/Procel, foi a primeira iniciativa desenvolvida para avaliar eficiência energética. Após isso, buscando contemplar de maneira mais abrangente as edificações, surgiu o Selo Casa Azul da CAIXA, destinado apenas para imóveis residenciais (PROVENZANO; BASTOS, 2017).
O PROCEL Edifica foi elaborado em 2003 a fim de construir as bases necessárias para racionalização do consumo de energia nas edificações brasileiras. Teve por base a estrutura do Programa Nacional de Conservação de Energia Elétrica (PROCEL), criado em 1985, com o objetivo de promover a redução dos impactos ambientais e garantir eficiência energética (PROCEL INFO, 2013).

O Selo Casa Azul foi lançado em 2010 pela Caixa Econômica Federal. Possui caráter voluntário e busca incentivar o uso racional de recursos no setor da construção civil, bem como a redução dos custos de manutenção e despesas mensais dos usuários. Além disso, almeja a promoção da conscientização de empreendedores e moradores acerca dos benefícios de uma construção sustentável. Após realizado o estudo de viabilidade técnica do empreendimento, baseado nos pré-requisitos de atendimento às regras do programa, o selo é emitido (CAIXA, 2010).

\section{METODOLOGIA}

A metodologia utilizada neste trabalho foi a Revisão Sistemática da Literatura (RSL). Ela é pautada em um rigor metodológico, aliado a um fluxo de etapas, as quais pretendem produzir uma avaliação crítica sobre dado tema. Este produto é viabilizado por meio de critérios objetivos e reprodutíveis de seleção e qualificação da amostra da pesquisa. A RSL se caracteriza por ser uma investigação focada em uma questão bem definida, em busca de identificar, selecionar, avaliar e sintetizar as evidências relevantes sobre um dado tema (GALVÃO; PEREIRA, 2014).

Primeiro deve-se estabelecer a questão motivadora. Esta pesquisa se insere em uma mais ampla que procurou responder à seguinte questão: "Qual é o panorama da NBR 15575 dentro da produção científica desde sua divulgação?".

De posse da questão motivadora, foi definido o termo de busca: "NBR 15575" ou "NBR 15.575". Essa diferenciação, com ponto e sem ponto, ocorreu pelo fato de ter sido verificado resultados diferentes nas pesquisas realizadas sem o uso das aspas, que retornou uma grande quantidade de arquivos que não diziam respeito à Norma de Desempenho. O recorte temporal utilizado foi de 2008 até 2018, isto é, desde a publicação da sua primeira versão.

Como é uma norma brasileira, esperava-se encontrar conteúdos referentes à mesma em universidades e periódicos brasileiros, sendo então escolhidos os seguintes bancos de dados: Periódicos da Coordenação de Aperfeiçoamento de Pessoal de Nível Superior (CAPES), Centro de Referência e Informação em Habitação (InfoHab), Catálogo de Teses e Dissertações da CAPES, Biblioteca Digital Brasileira de Teses e Dissertações (BDTD) e o Google Acadêmico. 
Após definidas as bases de dados, a próxima etapa compreendeu a coleta dos arquivos. O primeiro critério estabelecido foi o acesso integral aos textos. Caso essa condição não fosse satisfeita, o arquivo seria excluído de imediato. Além disso, somente Teses, Dissertações, Artigos de Periódicos e Artigos de Congresso foram considerados. De posse dos arquivos disponíveis e não repetidos, iniciou-se a análise dos títulos.

A priori, buscou-se no título relação com a Norma de Desempenho ou alguma das necessidades dos usuários. Em seguida, foi realizada a análise de resumos, eliminando-se todos aqueles que não faziam referência à norma. No Quadro 3 estão apresentados os resultados da aplicação dos filtros da RSL. Com a amostra final de 329 trabaIhos, foi possível estabelecer um panorama da produção científica brasileira referente à NBR 15575.

\begin{tabular}{|l|l|}
\hline Trabalhos & Total \\
\hline Iniciais & 1342 \\
\hline Disponíveis & 1176 \\
\hline Remoção Repetidos & 1054 \\
\hline Filtro 1 - Títulos & 654 \\
\hline Filtro 2 - Resumos & 329 \\
\hline
\end{tabular}

Quadro 3 - Resultado da RSL

Fonte: Autores (2020)

Foi realizado uma análise quantitativa dos dados dos trabalhos (análise bibliométrica), que pode ser encontrada em Hippert et al. (2020). Iniciou-se então, a etapa de análise qualitativa, a qual avaliava a relação do texto com a norma de desempenho. A leitura integral do corpo dos textos da amostra possibilitou a exclusão dos trabalhos que fossem irrelevantes para esta pesquisa, restando 292 títulos.

A leitura do corpo dos textos permitiu classificar cada trabaIho de acordo com os temas referentes às exigências da Norma de Desempenho. Além deles foi criado um grupo, intitulado "Gerais", que considerou os trabalhos que tratavam da Norma de Desempenho de maneira mais ampla como, por exemplo, a realização de estudos de casos avaliando edificações em relação aos requisitos da norma e o grupo "Comparação com outros documentos" que trata a comparação com normas internacionais e certificações ambientais (Quadro 4).

Vale ressaltar que há trabalhos que abrangem mais de uma exigência da norma e, portanto, foram considerados em todas elas. Por essa razão existe diferença entre o somatório de trabalhos por área e o número total de trabaIhos identificados na amostra.

O presente artigo considera os estudos relacionados à exigência de Adequação Ambiental, e os que comparam a NBR 15575 à normas de desempenho de outros países e selos/certificações ambientais. Dessa forma, RSL detectou 7 trabalhos referente à Adequação Ambiental, e 9 trabaIhos que comparavam a norma com outros documentos, como apresentado no Quadro 4.

\begin{tabular}{|l|l|l|l|}
\hline Tempo & $\begin{array}{l}\text { No de } \\
\text { trabalhos }\end{array}$ & Tema & $\begin{array}{l}\mathbf{N}^{\circ} \text { de } \\
\text { trabalhos }\end{array}$ \\
\hline $\begin{array}{l}\text { Desempenho } \\
\text { térmico }\end{array}$ & 107 & $\begin{array}{l}\text { Segurança } \\
\text { estrutural }\end{array}$ & 8 \\
\hline Gerais & 60 & $\begin{array}{l}\text { Adequação } \\
\text { ambiental }\end{array}$ & 7 \\
\hline $\begin{array}{l}\text { Desempenho } \\
\text { acústico }\end{array}$ & 58 & $\begin{array}{l}\text { Funcionalidade } \\
\text { e acessibilidade }\end{array}$ & 4 \\
\hline Durabilidade & 18 & Estanqueidade & 4 \\
\hline Manutenibilidade & 14 & $\begin{array}{l}\text { Segurança } \\
\text { contra fogo }\end{array}$ & 3 \\
\hline $\begin{array}{l}\text { Desempenho } \\
\text { lumínico }\end{array}$ & 11 & $\begin{array}{l}\text { Conforto tátil e } \\
\text { antropodinâmico }\end{array}$ & 1 \\
\hline $\begin{array}{l}\text { Comparação } \\
\text { com outros } \\
\text { documentos }\end{array}$ & 9 & \multicolumn{2}{|l}{} \\
\hline
\end{tabular}

Quadro 4 - Classificação dos trabalhos por temas Fonte: autores (2020)

\section{RESULTADOS E DISCUSSÃO}

Na Figura 1 é possível verificar que as pesquisas relacionadas à adequação ambiental concentraram suas publicações nos anos de 2014 e 2017. Trabalhos que estabelecem comparações da Norma de Desempenho com outras normas e selos de certificação, por sua vez, foram mais produzidos em 2014. Já entre as nove pesquisas que fazem comparações com a norma, quatro são de 2014.

Para facilitar a discussão, os resultados são apresentados em dois grupos: os trabalhos que tratam da adequação ambiental e aqueles referentes à comparação da NBR 15575 com outras normas/códigos de desempenho e selos de certificação ambiental.

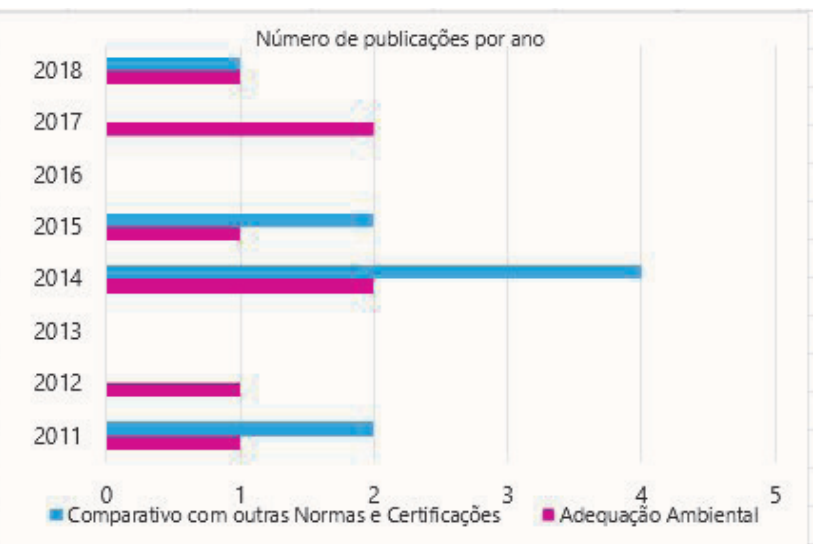

Figura 1 - Número de publicações x Ano de publicação Fonte: Autores (2020) 


\subsection{NBR 15575 e adequação ambiental}

A primeira parte da leitura das publicações encontradas foi composta por sete artigos que relacionavam a norma de desempenho, NBR 15575, à adequação ambiental (Quadro 5). Foram identificadas diferentes estratégias para abordar a questão: usuários, projeto, materiais e soluções alternativas, desempenho e gestão. Costa (2011) realizou entrevistas em um condomínio e observou que os usuários se sentem satisfeitos com suas habitações, mesmo o edifício carecendo de atendimento a vários dos requisitos da norma de desempenho.

Acompanhando o processo de projeto de uma empresa, Silva et al. (2014) constataram que a inadequação dos fornecedores à NBR 15575 compromete o atendimento das edificações aos requisitos da norma, afetando a relação da edificação com o meio ambiente.

Quanto aos materiais, Benavides (2012) tratou do uso do bambu (recurso natural renovável e abundante na região onde a pesquisa foi realizada) em Habitação de Interesse Social (HIS) e verificou que fatores causadores da deterioração do material podem ser facilmente combatidos. Ainda com relação aos materiais, Franco (2015) sugeriu a aplicação de resíduo sólido industrial de siderurgia como agregado para a fabricação de produtos moldados in-loco e pré-fabricados de concreto empregados na construção civil. Segundo o autor, para HIS o uso da escória de aciaria em argamassa não traz prejuízo na durabilidade dos elementos construtivos, nem promove contaminação aos mesmos, podendo ser comparados em nível de desempenho com os elementos construtivos baseados em agregados naturais. Ainda em relação às HIS, Perfeito (2017) verificou a possibilidade da utilização de contêineres marítimos como base para uma construção. As paredes utilizadas no projeto das HIS são de drywall, impactando o meio ambiente. Pode-se ainda utilizar a madeira como alternativa, o que, no entanto, requer mais estudos e algumas adaptações no projeto, já que o drywall também promove o isolamento acústico entre os cômodos.

Gerola (2014) avaliou o desempenho ambiental de HIS considerando o Selo Casa Azul, o RTQ-R e a própria NBR 15575, em um estudo de caso. O modelo de sistema de vedação vertical externo (tijolo cerâmico de seis furos com reboco de 2,5 cm interno e externo e pintura externa na cor clara) e a cobertura (sistema de telha de cerâmica cor laranja com câmara de ar maior que 0,50 m e forro de PVC) possibilitam que a edificação atinja um elevado nível de eficiência energética.

A vida útil do produto se relaciona com os impactos ambientais, uma vez que quanto maior for a durabilidade de um material, menor será a exploração dos recursos naturais, por exemplo.
Assim, Rezende, Brito e Freitas (2017) averiguam a vida útil do produto no contexto do Ecodesign e observam que é possível otimizar o desempenho ambiental respeitando as legislações ambientais, legislações infraconstitucionais e as normas regulamentadoras, como a norma de desempenho.

\begin{tabular}{|c|c|c|}
\hline Referência & Objetivo & Principais resultados \\
\hline Costa (2011) & $\begin{array}{l}\text { Percepção dos } \\
\text { usuários quanto à } \\
\text { sustentabilidade } \\
\text { das edificações }\end{array}$ & $\begin{array}{l}\text { A maior parte dos condômi- } \\
\text { nos não sabe o que é uma } \\
\text { edificação sustentável e/ou } \\
\text { de baixo impacto ambiental. }\end{array}$ \\
\hline $\begin{array}{l}\text { Silva et al. } \\
(2014)\end{array}$ & $\begin{array}{l}\text { Características da } \\
\text { implantação e ade- } \\
\text { quação ambiental } \\
\text { no processo de pro- } \\
\text { jeto de uma empresa }\end{array}$ & $\begin{array}{l}\text { Não há adequação dos forne- } \\
\text { cedores à norma, dificultando } \\
\text { o atendimento às condições } \\
\text { de adequação ambiental. }\end{array}$ \\
\hline $\begin{array}{l}\text { Benavides } \\
(2012)\end{array}$ & Bambu em HIS & $\begin{array}{l}\text { O uso do bambu já é uma } \\
\text { atitude sustentável e } \\
\text { reduz impactos ambien- } \\
\text { tais na construção civil. }\end{array}$ \\
\hline $\begin{array}{l}\text { Franco } \\
(2015)\end{array}$ & $\begin{array}{l}\text { Redução dos danos } \\
\text { ambientais dos } \\
\text { setores siderúrgicos } \\
\text { e da construção civil }\end{array}$ & $\begin{array}{l}\text { O uso de escória de aciaria } \\
\text { junto ao cimento Portland } \\
\text { promove o desempenho } \\
\text { térmico da edificação se } \\
\text { comparado ao uso de } \\
\text { agregados naturais. }\end{array}$ \\
\hline $\begin{array}{l}\text { Perfeito } \\
\text { (2017) }\end{array}$ & Contêineres em HIS & $\begin{array}{l}\text { Reciclagem de contêineres re- } \\
\text { duz os impactos ambientais. } \\
\text { Uso de drywall internamente } \\
\text { gera menores impactos que } \\
\text { construções tradicionais. }\end{array}$ \\
\hline $\begin{array}{l}\text { Gerola } \\
(2014)\end{array}$ & $\begin{array}{l}\text { Desempenho } \\
\text { ambiental de HIS }\end{array}$ & $\begin{array}{l}\text { As edificações não possuem } \\
\text { tecnologias suficientes para } \\
\text { minimizar impacto ambiental } \\
\text { na fase de uso e operação. }\end{array}$ \\
\hline $\begin{array}{l}\text { Rezende, } \\
\text { Brito e } \\
\text { Freitas } \\
(2017)\end{array}$ & $\begin{array}{l}\text { Utilização do } \\
\text { Ecodesign }\end{array}$ & $\begin{array}{l}\text { Relevante como ferramenta } \\
\text { de gestão ambiental com } \\
\text { possibilidade de otimizar o } \\
\text { desempenho ambiental. }\end{array}$ \\
\hline
\end{tabular}

Quadro 5 - A NBR 15575/2013 e a adequação ambiental Fonte: Autores (2020)

\subsection{NBR 15575 e avaliações de desempenho}

A segunda parte da leitura das publicações encontradas foi feita nos artigos que apresentavam uma comparação entre a norma de desempenho brasileira e as de outros países bem como entre a norma brasileira e sistemas de certificação. Os trabalhos que abordam as normas de desempenho estão no Quadro 6. O foco foi verificar as similaridades e diferenças entre as estruturas das normas e formas de implantação das mesmas.

Silva et al. (2011), Silva (2011) e Kern, Silva e Kazmierczak (2014) fazem uma comparação entre a implantação da NBR 15575/2008 e o Código Técnico de Edificação (CTE) espanhol. Os autores analisaram as duas normas e 
entrevistaram arquitetos da cidade espanhola de Logroño e engenheiros civis e arquitetos de empresas construtoras das cidades brasileiras de Porto Alegre e São Leopoldo.

Já Reus Netto e Czajkowski (2015) comparam a norma de desempenho brasileira com os códigos do Instituto Argentino de Normalizacion y Certificacion, IRAM da Argentina.
A NBR 15575 é também comparada com o código norte-americano, International Residential Code (IRC), por Miranda (2017).

Ainda na segunda parte da leitura das publicações encontradas foram considerados aqueles que fazem uma comparação da norma de desempenho com as certificações ambientais (Quadro 7).

\begin{tabular}{|c|c|c|}
\hline Referencias & $\begin{array}{l}\text { Comparar } \\
\text { com }\end{array}$ & Principais resultados \\
\hline $\begin{array}{l}\text { Silva et al. (2011), } \\
\text { Silva (2011) e } \\
\text { Kern, Silva e } \\
\text { Kazmierczak } \\
(2014)\end{array}$ & CTE & $\begin{array}{l}\text { Os profissionais entrevistados alegaram falta de clareza no código espanhol quanto à sustentabilidade, e que } \\
\text { os usuários, em muitos casos, não exigem estes conceitos em suas edificaçães por acreditarem que os mesmos } \\
\text { oneram o orçamento. } \\
\text { Na Espanha, para a construção de um edifício, o projeto deve ser aprovado pelo Colégio de Arquitetos ou Co- } \\
\text { légio de Engenheiros e ser autorizado por órgãos públicos municipais. É verificado se os projetos contemplam } \\
\text { todos os requisitos da norma para então ser liberada a execução. Após concluída a execução é feita uma se- } \\
\text { gunda avaliação, a partir de medições in situ, para verificar a compatibilidade do executado com relação ao } \\
\text { projeto e aos requisitos ao código. No Brasil, não há uma fiscalização por órgão oficial, nem na etapa de pro- } \\
\text { jeto e execução, nem após o término da construção. } \\
\text { O processo de implantação na Espanha foi gradativo, enquanto no Brasil foi integral, sem tempo hábil para os } \\
\text { profissionais brasileiros se adequarem à norma. A Espanha realizou palestras e discussões, além do "Programa } \\
\text { Líder" para divulgação da norma. No Brasil, não houve tal promoção. Além disto, na Espanha as normas são } \\
\text { gratuitas enquanto no Brasil são pagas. Por fim, no Brasil têm-se ainda a dificuldade de se encontrar fornece- } \\
\text { dores com produtos adequados ao atendimento da norma. }\end{array}$ \\
\hline $\begin{array}{l}\text { Reus Netto e } \\
\text { Czajkowski (2015) }\end{array}$ & IRAM & $\begin{array}{l}\text { Na Argentina a preocupação com desempenho de edificações já existia antes dos anos } 2000 \text {, enquanto no } \\
\text { Brasil a primeira ação que pontua desempenho de maneira ampla ocorreu em } 2008 \text {. } \\
\text { A dificuldade de aplicação da norma na Argentina deve-se à falta de legitimidade do documento, enquanto } \\
\text { no Brasil, deve-se à falta de profissionais qualificados. } \\
\text { A norma argentina é mais rigorosa que a brasileira quanto ao desempenho térmico, sendo duas vezes mais } \\
\text { exigente com transmitância térmica no verão e cerca de } 3,5 \text { vezes no período de inverno. }\end{array}$ \\
\hline Miranda (2017) & IRC & $\begin{array}{l}\text { O IRC deve ser aplicado em reformas, retrofit e edificações temporárias, enquanto a norma brasileira não. } \\
\text { Desempenho estrutural, lumínico, saúde, higiene e qualidade do ar e conforto tátil e antropodinâmico não } \\
\text { compõem o IRC em função do tipo de construção americana divergir das brasileiras em vários aspectos. }\end{array}$ \\
\hline
\end{tabular}

Quadro 6 - Comparativo da NBR 15575/2013 com normas de outros países

Fonte: Autores (2020)

\begin{tabular}{|c|c|c|}
\hline Referencias & $\begin{array}{l}\text { Comparar } \\
\text { com }\end{array}$ & Principais resultados \\
\hline Oliveira (2014) & $\begin{array}{l}\text { Selo Casa } \\
\text { Azul, } \\
\text { AQUA, } \\
\text { RQT-R }\end{array}$ & $\begin{array}{l}\text { AQUA é o que mais atende aos requisitos da NBR 15575/2013. O Selo Casa Azul apresenta uma estrutura } \\
\text { simplificada, atingindo apenas 3\% dos parâmetros abordados pela norma. Já o RQT-T é o que menos } \\
\text { atende aos critérios exigidos pela norma de desempenho. Esta diferença se justifica em função da nor- } \\
\text { ma estar voltada para os sistemas e componentes de edificações enquanto os sistemas de certificação } \\
\text { e avaliação são orientados para uma avaliação ambiental. }\end{array}$ \\
\hline $\begin{array}{l}\text { Oliveira e } \\
\text { Hippert (2014) }\end{array}$ & AQUA & $\begin{array}{l}\text { Relativo a implantação do empreendimento, as exigências topográficas e características do solo do ter- } \\
\text { reno são apresentadas de forma prescritiva. } \\
\text { O AQUA atende cerca de } 16 \% \text { do total de critérios presentes na NBR 15575/2013. Entre os critérios em } \\
\text { comum exigidos pela norma de desempenho, } 26 \% \text { são atendidos pelo AQUA em suas subcategorias. }\end{array}$ \\
\hline Costa et al. (2015) & $\begin{array}{l}\text { AQUA, } \\
\text { LEED } \\
\text { e ISO }\end{array}$ & $\begin{array}{l}\text { A ISO 21931/2010 é considerada genérica em quesitos ambientais, visto que não estipula níveis mínimos } \\
\text { de desempenho a serem alcançados. Porém, dentre os quatros instrumentos, é o único que considera } \\
\text { os aspectos sociais. } \\
\text { A vida útil da edificação é considerada no AQUA e na norma de desempenho mantendo coerência com } \\
\text { a legislação de acessibilidade existente, com o uso de materiais de fabricantes legais, entre eles os per- } \\
\text { tencentes no Programa Brasileiro de Qualidade e Produtividade no Habitat (PBQP-H). Já quanto à dura- } \\
\text { bilidade, o LEED não faz referência a mesma. } \\
\text { Os selos e as normas estabelecem exigências buscando a redução do consumo, a melhoria do de- } \\
\text { sempenho energético e o emprego de energia renovável. Além disto, buscam a redução do consumo } \\
\text { de recursos, reaproveitamento de água das chuvas, de águas cinzas e gestão de águas pluviais. }\end{array}$ \\
\hline $\begin{array}{l}\text { Pisani e Zein } \\
\text { (2014) }\end{array}$ & $\begin{array}{l}\text { Selo Casa } \\
\text { Azul, } \\
\text { Qualihab }\end{array}$ & $\begin{array}{l}\text { Os três instrumentos indicam parâmetros para desenvolvimento de habitações sociais de qua- } \\
\text { lidade. Porém, o país carece de ferramentas capazes de viabilizar o atendimento de parâme- } \\
\text { tros de desempenho nessas edificações. Além disso, falta desejo em atender os parâmetros da } \\
\text { NBR } 15575 \text { por parte dos setores envolvidos na produção de habitações sociais no Brasil. }\end{array}$ \\
\hline
\end{tabular}

Quadro 7 - Comparativo da NBR 15575 com certificações ambientais

Fonte: Autores (2020) 
Oliveira (2014) realizou um comparativo entre a certificação AQUA, a NBR 15575, o Selo Casa Azul da Caixa e o RQT-R. Como o AQUA é o que mais atende aos requisitos da norma, Oliveira e Hippert (2014) fizeram uma comparação entre os dois: AQUA e NBR 15575. As autoras reorganizaram a estrutura do referencial AQUA e da norma de desempenho, estabelecendo uma compatibilização de termos e nomenclaturas sem alteração do conteúdo e das informações de cada uma das referências averiguadas. $\mathrm{Na}$ estrutura elaborada "categoria" define as etapas do processo: Projeto, Conforto e Gestão enquanto as "subcategorias" correspondem as principais preocupações associadas a cada desafio ambiental (Quadro 8).

\begin{tabular}{|c|c|c|}
\hline Categoria/Subcategoria & AQUA & NBR 15575 \\
\hline \multicolumn{3}{|l|}{ PROJETO } \\
\hline Implantação do empreendimento & Sim & Sim \\
\hline $\begin{array}{l}\text { Escolha dos sistemas e pro- } \\
\text { cessos construtivos }\end{array}$ & Sim & Sim \\
\hline Qualidade sanitária dos ambientes & Sim & Sim \\
\hline Qualidade sanitária do ar & Parcial & Sim \\
\hline Qualidade sanitária da água & Parcial & Sim \\
\hline Funcionalidade e acessibilidade & Parcial & Sim \\
\hline Desempenho estrutural & Não & Sim \\
\hline Segurança no uso e ocupação & Parcial & Sim \\
\hline Segurança contra incêndio & Não & Sim \\
\hline Estanqueidade & Parcial & Sim \\
\hline Durabilidade & Parcial & Sim \\
\hline \multicolumn{3}{|l|}{ CONFORTO TÉRMICO } \\
\hline Eficiência da envoltória & Sim & Sim \\
\hline Ventilação natural & Sim & Sim \\
\hline Desempenho no verão & Não & Sim \\
\hline Desempenho no inverno & Sim & Sim \\
\hline \multicolumn{3}{|l|}{ CONFORTO LUMÍNICO } \\
\hline Iluminação natural & Sim & Sim \\
\hline Iluminação artificial & Sim & Sim \\
\hline \multicolumn{3}{|l|}{ CONFORTO ACÚSTICO } \\
\hline Ruídos de impacto & Sim & Sim \\
\hline Isolamento dos ruídos entre UH's & $\operatorname{Sim}$ & Sim \\
\hline Isolamento acústico de vedações & Sim & Sim \\
\hline Ruídos em equipamentos prediais & Não & Sim \\
\hline \multicolumn{3}{|l|}{ CONFORTO TÁTIL E ANTROPODINÂMICO } \\
\hline Conforto tátil e adaptação ergonômica & Não & Sim \\
\hline Adequação antropodinâmica & Não & Sim \\
\hline $\begin{array}{l}\text { Homogeneidade e plane- } \\
\text { za dos acabamentos }\end{array}$ & Não & Sim \\
\hline $\begin{array}{l}\text { Conforto na operação dos } \\
\text { sistemas prediais }\end{array}$ & Não & Sim \\
\hline \multicolumn{3}{|l|}{ GESTÃO DA ENERGIA } \\
\hline Dispositivos economizadores & Sim & Sim \\
\hline
\end{tabular}

\begin{tabular}{|c|c|c|}
\hline \multicolumn{3}{|l|}{ GESTÃO DA ÁGUA } \\
\hline Dispositivos economizadores & Parcial & Sim \\
\hline \multicolumn{3}{|l|}{ GESTÃO DA MANUTENÇÃO } \\
\hline $\begin{array}{l}\text { Manutenibilidade do edi- } \\
\text { fício e seus sistemas }\end{array}$ & Sim & Sim \\
\hline Resistência ao desgaste em uso & Não & Sim \\
\hline \multicolumn{3}{|l|}{ GESTÃO DOS RESÍDUOS } \\
\hline Gerenciamento de resíduos & Sim & Sim \\
\hline
\end{tabular}

Quadro 8 - Comparativo entre as categorias e subcategorias do referencial AQUA e da NBR 15575 Fonte: Adaptado de Oliveira e Hippert (2014)

No Quadro 8, "Sim" significa atendimento às exigências presentes na norma de desempenho; "Parcial" quando o sistema de certificação apresentar o mesmo tema de subcategoria, mas não apresentar critérios semelhantes aos exigidos pela NBR 15575; e, finalmente, "Não" para quando os critérios estabelecidos pela norma não são atendidos. É importante salientar que as subcategorias do AQUA são classificadas conforme o potencial de atendimentos aos critérios e indicadores exigidos pela norma de desempenho.

Costa et al. (2015) também analisaram a NBR 15575/2013 junto ao AQUA, além do LEED e da norma ISO 21931/2010. Já Pisani e Zein (2014) utilizaram a norma de desempenho junto ao Selo Casa Azul da Caixa Econômica Federal e o Programa de Qualidade da Construção Habitacional do Estado de São Paulo (Qualihab) para avaliar a qualidade do projeto e da construção de unidades habitacionais contratadas e entregues pelo Programa Minha Casa Minha Vida 1 e 2.

\subsection{Discussão}

A construção civil é um setor responsável pela geração de grandes impactos ambientais, desde a fase de construção, passando pela fase de uso e operação, até na demolição da edificação. A publicação da NBR 15575/2013, estabeleceu um desempenho mínimo a ser atendido, inclusive, visando uma redução no impacto ambiental durante a implantação da edificação e economias durante o seu uso, beneficiando o usuário. Entretanto, cabe ressaltar que a NBR 15575 passou a ser compulsória para os projetos protocolados nas prefeituras a partir de julho de 2013. Todos os projetos protocolados anteriormente, independentemente do momento de sua entrega, não são obrigados a cumprir a NBR 15575.

Nas edificações estudadas por Costa (2011) e Gerola (2014) os sistemas não foram pensados para garantir o desempenho ambiental da edificação. Entretanto, a utilização de tecnologia, muitas vezes simples, pode gerar grandes economias de água e energia, além de diminuir o 
impacto no meio ambiente. Gerola (2014) observou que as falhas ocorrem desde a fase de concepção do projeto, passando pela implantação e gerenciamento dos empreendimentos. Os sistemas devem ser pensados na fase de projeto para atender os requisitos de desempenho; a implantação deve buscar a redução da exploração e o consumo racional dos recursos naturais, e durante a vida útil da edificação deve-se garantir o funcionamento dos sistemas. Garantindo, assim, uma edificação mais sustentável.

A implantação e aplicação dos requisitos exigidos pela norma de desempenho e pelas certificações ambientais aumenta a complexidade do projeto. Os projetistas precisam especificar materiais e sistemas, e cabe aos fornecedores a adaptação de materiais e componentes às exigências de especificações técnicas, especialmente a disponibilização das informações sobre o desempenho (SILVA, et al., 2014). Assim, para a adoção da abordagem ambiental e a aplicação do conceito do desempenho, é necessária uma visão sistêmica do processo do produto edifício, envolvendo, muitas vezes, a requalificação dos profissionais, desde a cadeia de fornecedores de materiais e componentes até os projetistas e gestores da edificação.

Além disso, há uma dificuldade em relação à percepção da qualidade da edificação pelos usuários, gerada pela falta de conhecimento, não refletindo o real desempenho ambiental da edificação. O leigo não tem condições de avaliar nem de verificar o desempenho da edificação. Os entrevistados por Costa (2011), por exemplo, não sabem identificar o que torna uma edificação sustentável ou de baixo impacto ambiental.

Por outro lado, a publicação da norma de desempenho incentivou novas pesquisas para estudo de materiais, sistemas e soluções construtivas mais inovadoras. Dentre essas novas pesquisas, tem a utilização de Bambu na construção (BENAVIDES, 2012), HIS em contêineres (PERFEITO, 2017) e da escória de aciaria junto ao cimento Portland (FRANCO, 2015), que além de reduzir os resíduos siderúrgicos, aumenta o desempenho da edificação. Ademais, a aplicação do conceito de ecodesign e a gestão ambiental busca o equilíbrio entre os processos produtivos, os produtos e a sustentabilidade, que permite atingir uma maior qualidade ambiental da edificação, além de atender os requisitos presentes na Norma de Desempenho (REZENDE; BRITO; FREITAS, 2017).

Ao comparar a NBR 15575 com selos de certificação e/ ou códigos técnicos de outros países, os principais pontos abordados foram: a forma de divulgação e aplicação dos sistemas avaliativos; os critérios e exigências entre os documentos; as dificuldades de aplicação; a preocupação para qual fim se destinam e a existência de fiscalização para o cumprimento dos códigos.
Os trabalhos abordaram códigos de outros países, sendo eles o CTE da Espanha (SILVA et al.,2011; SILVA,2011; KERN; SILVA; KAZMIERCZAK, 2014), o IRAM da Argentina (REUS NETTO; CZAJKOWSKI, 2015) e o IRC dos Estados Unidos (MIRANDA, 2017). A implantação gradativa do CTE na Espanha parece ter sido mais assertiva do que a implantação integral da NBR 15575/2013 no Brasil. Além disso, a ampla discussão e projetos de divulgação do CTE permitiram maior acompanhamento e facilitaram a adaptação dos projetistas, construtoras, incorporadoras e demais agentes envolvidos, enquanto no Brasil as estratégias de divulgação e ensino da norma de desempenho não atenderam plenamente aos resultados esperados, prejudicando a adequação aos conceitos da norma. É possível verificar ainda que o fato de na Espanha existirem sistemas de verificação do atendimento ao CTE garante que os empreendimentos atendam aos níveis de desempenho esperados. Essa fiscalização ocorre na fase de projeto, através de órgãos públicos e do Colégio de Arquitetos ou Colégio de Engenheiros, e após a execução da obra com uma segunda verificação por órgãos públicos (SILVA et al.,2011; SILVA,2011; KERN; SILVA; KAZMIERCZAK, 2014). No Brasil, a fiscalização do poder público possui pouca perícia, levando muitas edificações a deixarem de ser auditadas. Isto abre margem para que algumas empresas deixem de cumprir várias exigências normativas.

A preocupação com desempenho das edificações já era uma temática discutida na Argentina desde 2000 através do IRAM. No entanto, as discussões da temática não influenciaram na consolidação de edificações com maior desempenho. Isto se deve pelo código argentino não ter a legitimidade de uma lei, como ocorre com a norma de desempenho no Brasil. Nesse caso, é encontrada dificuldade implementação eficaz de ambas as normativas, em que, no geral é cumprida apenas parcialmente (REUS NETTO; CZAJKOWSKI, 2015). A recomendação é que as verificações dos requisitos sejam avaliadas a nível municipal, para isso, seriam realizadas verificações dos requisitos antes da liberação da "licença para construção", e a comprovação do atendimento seria necessária para a liberação do "auto de conclusão de obra" (Habite-se). O fato do IRAM ser mais restritivo em relação ao desempenho térmico, se deve às características climáticas do território argentino, que apresenta variações térmicas mais altas e invernos mais rigorosos que no Brasil.

Já nos Estados Unidos, uma das grandes dificuldades encontradas na implantação do IRC é grande diversidade climática e geográfica presente no país, a solução encontrada para esse problema consiste em cada estado 
complementar a norma com as suas regionalidades. O código americano também contempla um maior número de casos, uma vez que considera retrofits e edificações temporárias, e abordam temas como planejamento da construção, manutenção e segurança à vida com maior eficácia, demonstrando ser um código mais completo e abrangente que a NBR 15575. Além disso, o cumprimento do IRC é fiscalizado através de um profissional especifico, que verifica o projeto antes de sua aprovação, e a cada etapa da execução há inspeções para concessão de autorização para a execução de uma nova etapa da obra, que aumenta a garantia do atendimento ao código (MIRANDA, 2017).

Quanto aos sistemas de certificação AQUA, Selo Casa Azul e o RQT-R verificou-se que nenhum atende toda a norma desempenho brasileira, isso porque as certificações têm por finalidade, em sua maioria, apenas aspectos ambientais, enquanto a NBR 15575 é mais abrangente. No entanto, os selos apresentam semelhanças com a norma e é possível perceber que as certificações ambientais e energéticas já se preocupam com o desempenho dos empreendimentos, adquirindo em suas metodologias de avaliação exigências semelhantes às recomendadas pela NBR 15575/2013.

A norma NBR 15575 apresenta no total cento e cinquenta e seis critérios distribuídos nas seis partes. O selo AQUA atende cerca de $16 \%$ de todos os requisitos na norma, o Selo Casa Azul atende a apenas 3\% (OLIVEIRA, 2014; OLIVEIRA; HIPPERT, 2014). O AQUA, apesar de ser internacional, foi adaptado a realidade brasileira, atendendo uma maior quantidade de requisitos da Norma de Desempenho, tornando-se, portanto, uma ferramenta de avaliação de desempenho ambiental mais eficiente. (OLIVEIRA, 2014; OLIVEIRA; HIPPERT, 2014).

O LEED, por sua vez, também é um selo internacional e que não foi desenvolvido para as especificidades do território brasileiro, mas distingue-se do AQUA devido ao fato de não contemplar nenhuma adaptação para o contexto nacional. Apesar disso, o sistema LEED ainda apresenta vários aspectos importantes e que são viáveis de serem aplicados no Brasil quando se busca uma edificação sustentável, como consumo e reuso de materiais, água e energia (COSTA et al. (2015).

O Selo Casa Azul apresenta uma estrutura mais simplificada, tanto na metodologia para atendimento aos critérios, quanto na quantidade de critérios exigidos. Além disso, dos 53 critérios presentes na certificação, o atendimento de apenas 19 já garante o selo bronze. O RTQ-R aborda apenas aspectos relacionados ao desempenho energético, sendo muito específico quando comparado à norma de desempenho (OLIVEIRA, 2014).
No contexto geral, os sistemas de certificação e avaliação ambiental já utilizam em suas metodologias o conceito de desempenho, mesmo não atendendo a todos os requisitos exigidos na norma brasileira de desempenho. Além disso, as empresas que já buscavam certificações de seus projetos e edificações tendem a ter maior facilidade para se adaptar à NBR 15575/2013.

$\mathrm{O}$ atendimento aos requisitos da norma de desempenho garante uma edificação mais sustentável e com baixo impacto ambiental. Diferente das certificações que são facultativas, a norma tem caráter obrigatório, mas ambos incentivam um ambiente construído de qualidade e que satisfaça as necessidades do usuário.

\section{CONSIDERAÇÕES FINAIS}

O método utilizado, a RSL, se mostrou eficaz uma vez que permitiu o estabelecimento de um caminho consistente de um universo geral a resultados específicos. A classificação dos resultados em grupos relacionados às exigências dos usuários permitiu traçar um panorama geral das pesquisas realizadas sobre a NBR 15575 e que se relacionam com Adequação Ambiental, com normas/ códigos de desempenho, bem como selos de certificação ambiental. A partir deste panorama foi possível identificar a contribuição dos aspectos ambientais da NBR 15575 a serem considerados nas edificações habitacionais e também estabelecer uma discussão acerca da adequação ambiental e da norma de desempenho, cumprindo, portanto, o objetivo deste estudo.

Os principais erros que potencializam danos ambientais ocorrem na fase de concepção do projeto, seguida da implantação e gerenciamento do empreendimento. Isso se agrava no momento que os profissionais envolvidos não atuam de acordo com as diretrizes da NBR 15575 e que os usuários das edificações não reivindicam ao setor da Construção Civil e aos órgãos públicos competentes, fiscalizações que garantem empreendimento com elevados índices de desempenho. A pouca manifestação dos usuários diante do desempenho das edificações se sustenta no fato de não compreenderem a amplitude do tema e seu impacto nos diversos sistemas de uma edificação.

Entretanto, o uso de tecnologias visando a melhor adequação ambiental do empreendimento gera uma redução significativa de recursos naturais, diminuindo, portanto, impacto ambiental do empreendimento. Novas pesquisas foram incentivadas a partir da NBR 15575, como o uso de Bambu na construção, o reaproveitamento de contêineres e o acréscimo de escória de aciaria ao cimento Portland. 
Entre os resultados da pesquisa, um tema muito abordado foram as habitações de interesse social no Brasil. Os trabalhos apontam que as partes envolvidas em HIS precisam estar interessadas em realizar uma edificação com qualidade para o usuário, atendendo a critérios mínimos de desempenho. Desde 2017, o Programa Brasileiro da Qualidade e Produtividade do Habitat (PBQP-H) incorporou a NBR 15575 ao regimento do Sistema de Avaliação da Conformidade de Empresas de Serviços e Obras da Construção Civil (SiAC). Isso reforça o atendimento aos requisitos da norma de desempenho, uma vez que o atendimento ao programa é necessário para obtenção de financiamentos em instituições de créditos públicas (como Caixa e Banco do Brasil) e privadas e a participação no programa Minha Casa Minha Vida. Entretanto, ainda não existe uma fiscalização adequada do cumprimento dos requisitos da norma. Caberia avaliar, conforme proposto por Gerola (2014) se as prefeituras, a Caixa Econômica Federal e demais órgãos envolvidos em financiamentos pudessem fiscalizar o cumprimento da norma. Para a Caixa Econômica Federal, é interessante que no mínimo as edificações de interesse social atendam ao Selo Casa Azul, uma vez que este é o selo criado pela própria entidade financiadora estabelecendo alguns critérios a serem atendidos, sobretudo no quesito ambiental.

Relativo à comparação da NBR 15575 com selos e certificações e/ou códigos técnicos de outros países, notou-se distinção entre a forma de divulgação e aplicação dos sistemas avaliativos, os critérios e exigências entre os documentos, as dificuldades de aplicação, a preocupação para qual fim se destinam e a existência de fiscalização para o cumprimento dos códigos. Entre os códigos técnicos, o CTE foi o que teve maior sucesso em sua política de implantação, o que se contrapõe à norma de desempenho, uma vez que as diretrizes adotadas para essa finalidade, embora tenham sido aplicadas, apresentaram resultados diferentes dos alcançados pelo código espanhol. Os selos e ferramentas de avaliação ambiental demonstram preocupação com o desempenho da edificação e já incorpora alguns critérios abordados pela NBR 15575.

\section{REFERÊNCIAS}

ASSOCIAÇÃO BRASILEIRA DE NORMAS TÉCNICAS (ABNT). NBR 15575: Edificações habitacionais Desempenho. Rio de Janeiro, 2013

BENAVIDES, Andrea Salomé Jaramillo. Proposta de sistema construtivo para habitação de interesse social com bambu guadua: um estudo de caso no equador. 2012. Dissertação (Mestrado em Arquitetura e Urbanismo). Programa de Pós-Graduação em Arquitetura e Urbanismo, Universidade Federal de Santa Catarina, Florianópolis, 2012.

BORGES, Carlos A. de Moraes; SABBATINI, Fernando H. o Conceito de desempenho de edificações e a sua importância para o setor da construção civil no Brasil. Boletim Técnico da Escola Politécnica da USP, 2008.

BRASIL. Lei no. 8.078, de 11 de setembro de 1990.

Código de Defesa do Consumidor. Dispõe sobre a proteção do consumidor e dá outras providências. Brasília; $169^{\circ}$ da Independência e $102^{\circ}$ da República. 11 de setembro de 1990. Disponível em: http://www. planalto.gov.br/ccivil_03/Leis/L8078.htm. Acesso em: 29 de maio de 2019

BRUNDTLAND, Gro Harlem. Report of the World Commission on Environment and Development: Our Common Future. United Nations. Oslo, 1987.

CAIXA. Boas Práticas para Habitação mais Sustentável. São Paulo: Ed. Páginas \& Letras, 2010.

CANAZARO, C.C., KERN, A.P. Análise de um Prédio Certificado LEED - Novas Construções na Versão Atual da Certificação de Operação e Manutenção. In: ENCONTRO NACIONAL DE TECNOLOGIA DO AMBIENTE CONSTRUÍDO, 178., 2018, Foz do Iguaçu. Anais[...] Porto Alegre: ANTAC, 2018.

COSTA, Lia Geovana Sala. Benefícios da adequação ambiental na etapa de uso de um condomínio residencial. 2011. Dissertação (Mestrado em Arquitetura e Urbanismo). Programa de Pós-Graduação em Arquitetura e Urbanismo, Universidade Federal de Santa Catarina, Florianópolis, 2011.

COSTA, M. C.; ALMEIDA, M.; CUNHA, R. D. A.; CÉSAR, S. F. Estudo comparativo entre as normas ISO 21931:2010, NBR 15575 e os requisitos das Certificações AQUA e LEED. In: CONNECTING PEOPLE AND IDEAS, PROCEEDINGS OF EURO ELECS 2015, 2., 2015, Guimarães. Anais [...]. Guimarães: 2015, p.1261-1270.

DOAN, D. T; GRAFFARIANHOSEINI, A; NAISMITH, N; ZHANG, T; GRAFFARIANHOSEINI, A.; TOOKEY, J. A critical comparison of green building rating systems. Building and Environment, v123, p.243-260, 2017. DUAN, H.; LI, J. Construction and demolition waste management: China's lessons. Waste Management \& Research, v. 34, n. 5, 2016.

FRANCO, Luisa Carvalho. Concretos e argamassas sustentáveis aplicados à habitação de interesse social. 2015. Dissertação (Mestrado em Engenharia Civil) - Programa de Pós-Graduação, Escola de Minas, 
Universidade Federal de Ouro Preto, Ouro Preto, 2015. GALVÃO, Taís Freire; PEREIRA, Mauricio Gomes. Revisões sistemáticas da literatura: passos para sua elaboração. Epidemiol. Serv. Saúde, Brasília, v. 23, n.1, p. 183-184, jan-mar 2014.

GEROLA, Gleison Mendes. Avaliação do desempenho ambiental de habitações de interesse social em Sarandi - Maringá - Paiçandu/PR. 2014. Dissertação (Mestrado em Engenharia Urbana). Programa de Pósgraduação em Engenharia Urbana, Universidade Estadual de Maringá, Maringá, 2014. HIPPERT, M. A. S.; NUNES, V. D. L.; FARIA, S; CARVALHO, A. R., RUBIM, D. F. Norma Brasileira de Desempenhp - NBR 15575: Uma Revisão Sistemática de Literatura. In: HIPPERT, M. A. S. Ambiente Construído e Seu Desempenho. Juiz de Fora: Editora UFJF, 2020. (Em publicação)

INSTITUTO BRASILEIRO DE GEOGRAFIA E ESTATÍSTICA (IBGE) - Indicadores de Desenvolvimento Sustentável - IDS. 2020. Disponível em: < https://sidra.ibge.gov.br/pesquisa/ids/tabelas> acesso em: 06 maio de 2020.

JALAEI, F.; JALAEI, F.; MOHAMMADI, S. Na integrated BIM-LEED application to automate sustainable design assessment framework at the conceptual stage of building projects. Sustainable Cities and Society, v. 53, 2020.

KERN, A. P.; SILVA, A.; KAZMIERCZAK, C. S. O processo de implantação de normas de desempenho na construção: um comparativo entre a Espanha (CTE) e Brasil (NBR 15575/2013). Gestão e Tecnologia de Projetos, São Paulo, v. 9, n. 1, p. 89-101, jan./jun. 2014.

LACERDA, C. S.; CARSALADE, F. L.; ASSIS, E. S. As certificações LEED e AQUA-HQE em edifícios comerciais no Brasil e a agregação de valor. In: ENCONTRO NACIONAL DE TECNOLOGIA DO AMBIENTE CONSTRUÍDO, 17., 2018, Foz do Iguaçu. Anais[...] Porto Alegre: ANTAC, 2018.

LEE, E. Indoor environmental quality (IEQ) of LEEDcertified home: Importance-performance analysis (IPA). Building and Environment, v. 149, p.571-581, 2019.

LÓPEZ, C. D; CARPIO, M; MARTÍN-MORALES, M; ZAMORANO, M; A comparative analysis of sustainable building assessment methods. Sustainable Cities and Society, v. 49, 2019.

MATEUS, R; BRAGANÇA, L; Sustainability assessment and rating of buildings: Developing the methodology SBTooIPT-H. Building and Environment. 2011; 26:
1962 -1971. DOI: 10.1016/j.buildenv.2011.04.023

MATOS, Bruna Farhat. Construção sustentável: panorama nacional da certificação ambiental. 2014. Dissertação (Mestrado em Ambiente Construído) Universidade Federal de Juiz de Fora, Juiz de Fora, 2014.

MAUÉS, L. M. F; NASCIMENTO, B. M. O.; LU, W.; XUE, $F$. Estimating construction waste generation in residential buildings: A fuzzy set theory approach in the Brazilian Amazon. Journal of Cleaner Production, v. 265, 2020.

MIRANDA, Maria Aparecida de Oliveira. Sustentabilidade Nas Normas Para Edificações Habitacionais: Uma Análise Comparativa Da ABNT NBR 15575 - Desempenho, Com O International Residential Code (IRC). 2017. Dissertação (Mestrado em Ambiente Construído e Patrimônio Sustentável). Mestrado em Ambiente Construído e Patrimônio Sustentável, Universidade Federal de Minas Gerais, Belo Horizonte, 2017.

OLIVEIRA, V. M.; HIPPERT, M. A. S. Desempenho de empreendimentos habitacionais: uma análise comparativa dos critérios contidos na NBR 15575 e no referencial AQUA. In: ENCONTRO NACIONAL DE TECNOLOGIA DO AMBIENTE CONSTRUÍDO, 15., 2014, Maceió. Anais [...]. Porto Alegre: ANTAC 2014.

OLIVEIRA, Vivian Moreno de. Sistemas de Certificação Ambiental e A Norma Brasileira de Desempenho. 2014. Dissertação (Mestrado em Ambiente Construido) - Programa de Pós-Graduação em Ambiente Construído, Faculdade de Engenharia, Universidade Federal de Juiz de Fora, Juiz de Fora, 2014.

PELLIZZETTI, Cristina Shoji. Certificação ambiental de Habitações LEED e as mudanças na gestão da construção civil sustentável na América Latina. MIX Sustentável, Florianópolis, v. 3, n.1, p. 36-43, out-mar 2017.

PERFEITO, Perivaldo Alves. Avaliação do ciclo de vida de uma habitação de interesse social construída a partir de contêineres marítimos reciclados. 2017. Dissertação (Mestrado em Engenharia e Tecnologia de Materiais). Programa de Pós-Graduação em Engenharia e Tecnologia de Materiais (PGETEMA), Pontifícia Universidade Católica do Rio Grande do Sul, Porto Alegre, 2017.

PISANI, M. A. J.; ZEIN, L. V. Habitação Social Brasileira no século $X X I$ : quantidade $x$ qualidade. ENCONTRO DA ASSOCIAÇÃO NACIONAL DE PESQUISA E PÓSGRADUAÇÃO EM ARQUITETURA E URBANISMO, 3., 
2014, São Paulo. Anais [...]. São Paulo: 2014.

Procel INFO. Procel Edifica. Disponível em: <http:// www.procelinfo.com.br>. Acesso em: 13 de agosto de 2019.

PROVENZANO, Denise de C.; BASTOS, Leopoldo E. G. Avaliação da sustentabilidade de um empreendimento de HIS do PMCMV, através do selo casa azul. MIX Sustentável, Florianópolis, v.3, n. 2, p.14-23, mai 2017. REZEND, G. B. M.; BRITO, A. L. C.; FREITAS, L. S. A prática do ecodesign na construção civil e a busca pelo direito fundamental ao meio ambiente ecologicamente equilibrado. HOLOS, Natal, v.4, ano 33, p. 266-281, jul. 2017 REUS NETTO, G.; CZAJKOWSKI, J. D. Comparación Entre las Normas de Desempeño Térmico Edilício de Argentina y Brasil. Ambiente Construído, Porto Alegre, v. 16, n. 1, p. 105-122, jan./mar. 2016.

SILVA, A. T. da; KERN, A. P.; KAZMIERCZAK, C. de S.; GONZÁLEZ, M. A. S.; CASTRO, R. Comparação entre os processos de implantação do Código Técnico das Edificações na Espanha e NBR 15.575/2008 - Desempenho no Brasil. In: Encontro Nacional Edificações e Comunidades Sustentáveis 6.; Encontro Latino-americano sobre Edificações e Comunidades Sustentáveis 4., 2011, Vitória. Anais [...] Vitória: 2011. de Certificação Ambiental Aqua frente às Dimensões da Sustentabilidade. In: ENCONTRO NACIONAL DE TECNOLOGIA DO AMBIENTE CONSTRUÍDO, 17., 2018, Foz do Iguaçu. Anais [...] Porto Alegre: ANTAC, 2018 WANG, J.; WU, H.; DUAN, H.; ZILLANTE, G.; ZUO, J.; YUAN, H. Combining life cycle assessment and Building Information Modelling to account for carbono emission of building demolition waste: A case study. Journal of Cleaner Production, v. 172, p. 3154 3166, 2018.

WILDE, P.; Ten questions concerning building performance analysis. Bulding and Environment, v. 153, p.110-117, 2019.

ZARGHAMI, E.; FATOUREHCHI, D. Comparative analysis of rating systems in developing and developed countries: A systematic review and a future agenda towards a regionbased sustainability assessment. Journal of Cleaner Production, v. 254, 2020.

ZHU, W.; ZHANG, Z; LI, X.; FENG, W.; LI, J. Assessing the effects of technological progress on energy efficiency in the construction industry: A case of China. Journal of Cleaner Production, v. 238, 2019.

\section{AGRADECIMENTOS}

À Universidade Federal de Juiz de Fora e à CAPES. processos de implantação do código técnico das edificações na Espanha e a NBR 15.575/2008 Desempenho - no Brasil. 2011. Dissertação (Mestrado em Engenharia Civil). Programa de pós-graduação em Engenharia Civil, Universidade do Vale do Rio dos Sinos, São Leopoldo, 2011.

SILVA, V. G. Avaliação da sustentabilidade de edifícios de escritórios brasileiros: diretrizes e base metodológica. 2003. 210 p. Tese (Doutorado em Engenharia Civil) Departamento de Engenharia de Construção Civil, Universidade de São Paulo, São Paulo, 2003.

SILVA, V. G. Metodologias de avaliação de desempenho ambiental de edifícios: estado atual e discussão metodológica. Finep 2386/04. São Paulo, 2007.

SLVA, A. T.; KERN, A. P.; PICCOLI, R.; GONZÁLEZ, M. A. $S$. Novas exigências decorrentes de programas de certificação ambiental de prédios e de normas de desempenho na construção. Arquitetura Revista, São Leopoldo, v. 10, n. 2, p. 105-114, jul/dez 2014.

SOUZA, T. D; GHISI, E. Harvesting Rainwater from scaffolding platforms and walls to reduce potable water consumption at buildings construction sites. Journal of Cleaner Production, v. 258, 2020.

TIBÚRCIO, T. M. S.; OLIVEIRA, M. G.; Análise do Sistema 


\section{AUTORES}

ORCID: https://orcid.org/0000-0003-2767-4374

ALDO RIBEIRO DE CARVALHO, | Universidade Federal de Juiz de Fora | Engenharia Civil | Juiz de Fora, MINAS GERAIS (MG) - Brasil | Correspondência para: Rua Rei Alberto, 62, apto 1303 - Centro, Juiz de Fora- MG, 36016-300 | E-mail: aldo. carvalho@engenharia.uff.br

ORCID: https://orcid.org/0000-0001-7825-6848

VITOR DIAS LOPES NUNES | Universidade Federal de Juiz de Fora | Engenharia Civil | Juiz de Fora, MINAS GERAIS (MG) Brasil | Correspondência para: Rua José Francisco Macêdo, 173 - Guararema, Alegre - ES.| E-maill: dias.vitor36@gmail. com

ORCID: https://orcid.org/0000-0001-6043-9718

DIANA FIORI RUBIM | Universidade Federal de Juiz de Fora | Engenharia Civil | Juiz de Fora, MG - Brasil | Correspondência para: Avenida Presidente Itamar Franco, 728, apto 803 - Centro, Juiz de Fora - MINAS GERAIS (MG), 36010-020 | E-mail: diana.rubim@engenharia.uff.br

ORCID: https://orcid.org/0000-0003-3604-0111

MARIA APARECIDA STEINHERZ HIPPERT, Dra. | Universidade Federal de Juiz de Fora | Engenharia Civil | Juiz de Fora, MINAS GERAIS (MG) - Brasil | Correspondência para: Campus da UFJF, 4a Plataforma do Setor de Tecnologia - Martelos, Juiz de Fora - MG, 36036-330 | aparecida.hippert@uff.edu.br

\section{COMO CITAR ESTE ARTIGO}

CARVALHO, Aldo Ribeiro de; NUNES, Vitor Dias Lopes; RUBIM, Diana Fiori; HIPPERT, Maria Aparecida Steinherz. NBR 15575, Adequação Ambiental e Avaliação De Desempenho. MIX Sustentável, [S.I.], v. 6, n. 3, p. 55-70, jun. 2020. ISSN 24473073. Disponível em:<http://www.nexos.ufsc.br/index.php/mixsustentavel>. Acesso em: dia mês. ano. doi:https://doi. org/10.29183/2447-3073.MIX2020.v6.n3.55-70. 
